\title{
A Comprehensive Treatment Protocol for Lingual Frenectomy with Combination of Lasers and Speech Therapy: Two Case Reports
}

\author{
${ }^{1}$ Vidyaa Hari lyer, ${ }^{2}$ Sujatha Sudarsan
}

\begin{abstract}
Lingual frenectomy is the procedure that involves removal of a band of tissue, the lingual frenulum which connects the tongue with floor of the mouth. The procedure is generally safe, but caution is necessary as it can cause severe, permanent or untreatable pain, and nerve damage. This procedure could be partial removal of frenum or repositioning of the frenum termed as "frenoplasty" or "frenotomy", and complete removal of frenum termed as "frenectomy". Laser frenectomy results are in a lower risk of relapse, such as adhesion, and hence the prognosis is superior to those treated by traditional methods. This article highlights the advantages of using lasers as a treatment option for lingual frenectomy and aftercare with speech therapy for rehabilitation of the patients.
\end{abstract}

Keywords: Articulation disorders, Frenectomy, Frenoplasty, Frenotomy, Frenulectomy, Frenulotomy, Lingual frenum, Speech therapy.

How to cite this article: lyer VH, Sudarsan S. A Comprehensive Treatment Protocol for Lingual Frenectomy with Combination of Lasers and Speech Therapy: Two Case Reports. Int J Laser Dent 2015;5(1):12-21.

Source of support: Nil

Conflict of interest: None

\section{INTRODUCTION}

Tongue is an important organ, which helps a person in speech and articulation and different tongue movements including tongue tip elevation, retraction, protrusion, and grooving. Proper positioning of the frenum enables the person to pronounce the alphabets properly and aids in phonetics. In some people, the frenulum is attached to the tip of the tongue, making its movements restricted or immobile. Sometimes, the frenum can be thick, tight, or large, causing midline diastema between the maxillary or mandibular anterior teeth, or causing gingival pull leading to recession of gingiva in the anteriors and posteriors.

${ }^{1}$ Director and Chief, ${ }^{2}$ Audiologist and Speech Pathologist

${ }^{1,2}$ Smile Dental Clinic, Chennai, Tamil Nadu, India

Corresponding Author: Vidyaa Hari lyer, Director and Chief, Smile Dental Clinic, Chennai, Tamil Nadu, India, email: vidyaasmiledentalclinic@gmail.com
Ankyloglossia, ${ }^{1-3}$ commonly known as tongue-tie, ${ }^{4}$ is a congenital oral anomaly characterized by a short lingual frenulum. The lingual frenum is generally thin vertical fold of tissue with attachments that connects the middle of sublingual face of the tongue to the floor of the mouth. Orofacial functions, such as sucking, chewing, swallowing, speech, phonetics, and articulation are carried out by tongue movements. These movements can be altered due to positioning of the frenum. Frenectomy is the usual procedure to release the lingual frenulum done traditionally using scalpel, electrocautery, and now with soft or hard tissue lasers.

There are various issues commonly associated with tongue-tie:

- Breast feeding: Tongue-tie ${ }^{5}$ does not aid the infant to latch to his mother and hence, makes feeding difficult. This further affects the psychological bonding between the mother and the child. ${ }^{6-9}$

- Speech development: Alphabets like " $\mathrm{r}$ " and "1" are pronounced with ease by a normal tongue. People with ankyloglossia ${ }^{10}$ compensate well and try to sound close to normalcy except for slight hissing sound.

- Dental health: Dental caries can occur due to food debris not being removed by the tongue's sweeping action.

- Periodontal health: Gingivitis and halitosis may also be seen.

- Eating and digestion: Some children can be messy with food because they are unable to roll their tongues. This leads to cracked lips as they are unable to wet their lips due to a restricted mobility.

\section{CASE REPORTS}

This article highlights two case reports where soft and hard tissue lasers were used to perform frenectomy procedures. Since both the patients were adults, speech therapy was an addition to the treatment protocol, which helped in easy rehabilitation following treatment.

\section{Case 1}

A 59-year-old male patient had visited our dental clinic and presented to us with complaints of dental caries and loss of his lower anterior teeth (Figs 1 and 2). The 


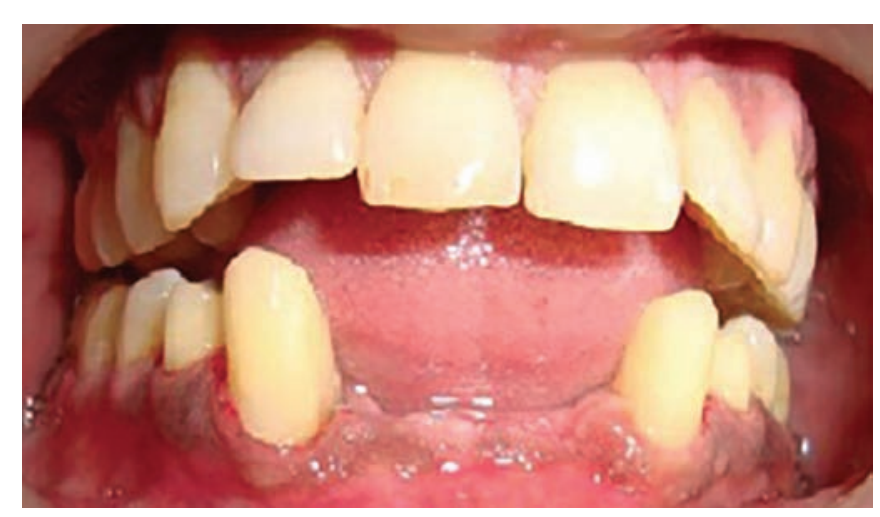

Fig. 1: Missing mandibular central and lateral incisors (case 1)

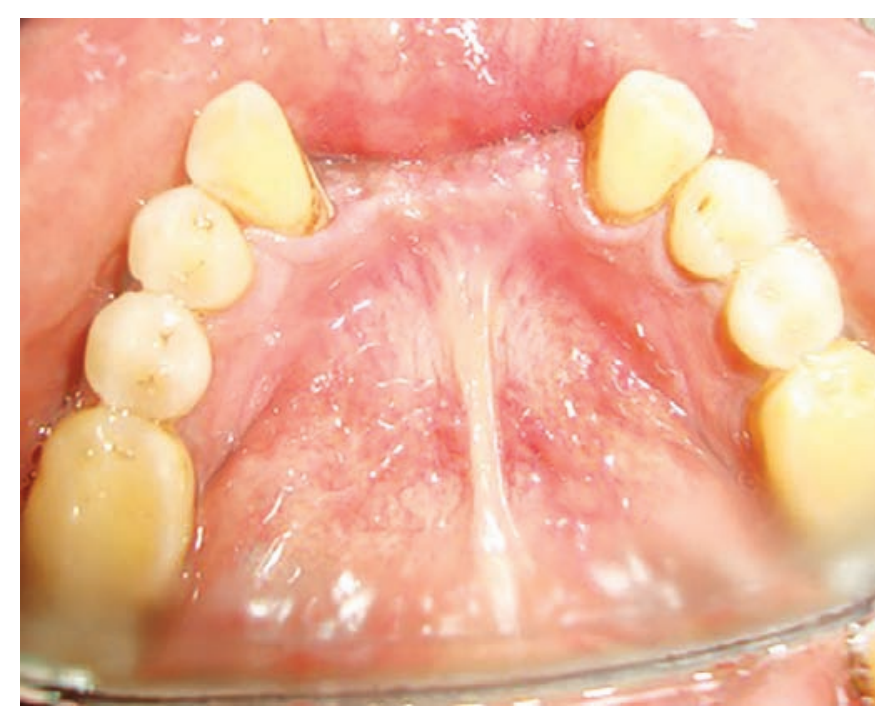

Fig. 3: Mirror image of the short and thick lingual frenum (case 1)

patient required replacement of his missing teeth with a fixed option. On clinical examination, he had thick and short lingual frenum (Fig. 3), which restricted the movement of the tongue. General dental prophylaxis and treatment protocols were discussed with the patient. The patient was hypertensive and diabetic for last 10 years and has been under constant monitoring by a general physician. The lingual frenum was suggested to be removed either using traditional methods, with scalpel and suturing done, or using lasers. The patient preferred to get the procedure done with lasers.

A $940 \mathrm{~nm}$ diode (Ezlase, Biolase, USA) was used for the removal of lingual frenum. Diode surgical soft tissue lasers are class IV lasers, and all laser safety precautions have to be followed precisely, such as wearing of protective eyewear (Fig. 4) specific to the wavelength by the patient, a dental assistant and the operating dentist, minimizing reflective surfaces in the operating site, reducing the traffic within the operatory, restricting the use of alcohol-based local anesthetic sprays to prevent hazards within the operatory site, and the presence of

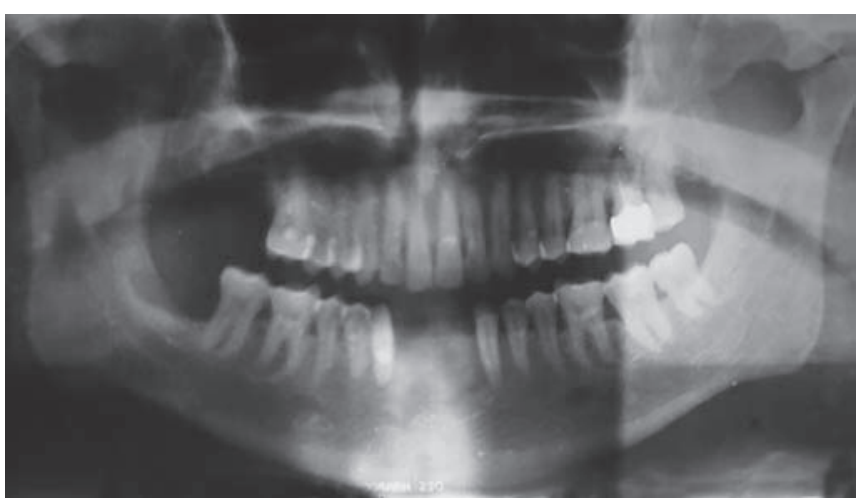

Fig. 2: Orthopantamograph showing missing 31, 32, 41, and 42 (case 1)

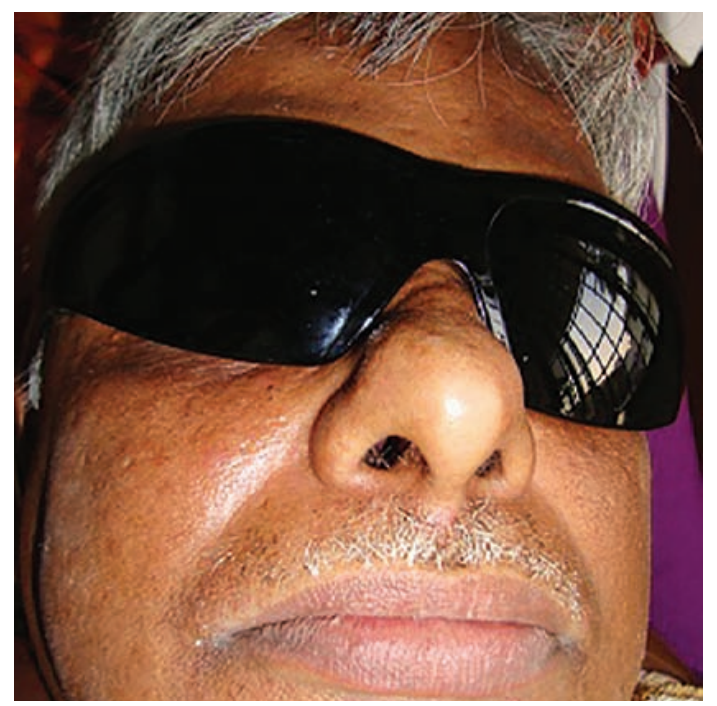

Fig. 4: Patient wearing laser-protected eyewear (case 1)

a laser safety officer to ensure all safety protocols are adhered to control the hazards.

Local anesthetic gel (Precaine - lidocaine 8\%, dibucaine $0.8 \%$ in a flavored aqueous base) was applied on the frenum and diode laser disposable tip, with $400 \mu \mathrm{m}$ thickness $4 \mathrm{~mm}$ length, was used (Fig. 5). The laser parameter used was $1 \mathrm{~W}$ continuous wave (Fig. 6). The tip was used to ablate the frenum thereby bringing about the frenectomy procedure (Fig. 7). The patient was comfortable throughout the procedure. Postoperative instructions were given to the patient to have cold soft diet and, in case of pain, to take analgesic tablets along with topical application of gels. The patient was recalled after 24 hours for a followup (Fig. 8). The patient was absolutely comfortable and had not taken any medications in spite of being medically compromised. The patient was further called for a 3-day and 1-week follow-up (Fig. 9). Consultations with a speech therapist were interspersed between the dental appointments within the clinic, and the patient was guided to pronounce words phonetically correct. Tooth preparation was done on $33,34,43$, and 44 to receive the fixed prosthe- 


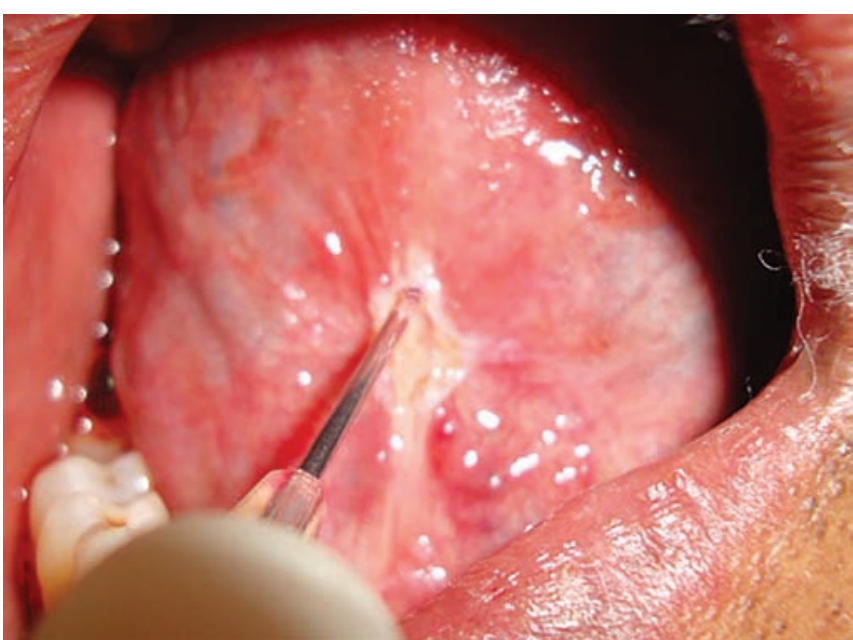

Fig. 5: A $940 \mathrm{~nm}$ diode laser with $400 \mu \mathrm{m}$ thick and $4 \mathrm{~mm}$ long disposable tip used to perform lingual frenectomy (case 1)

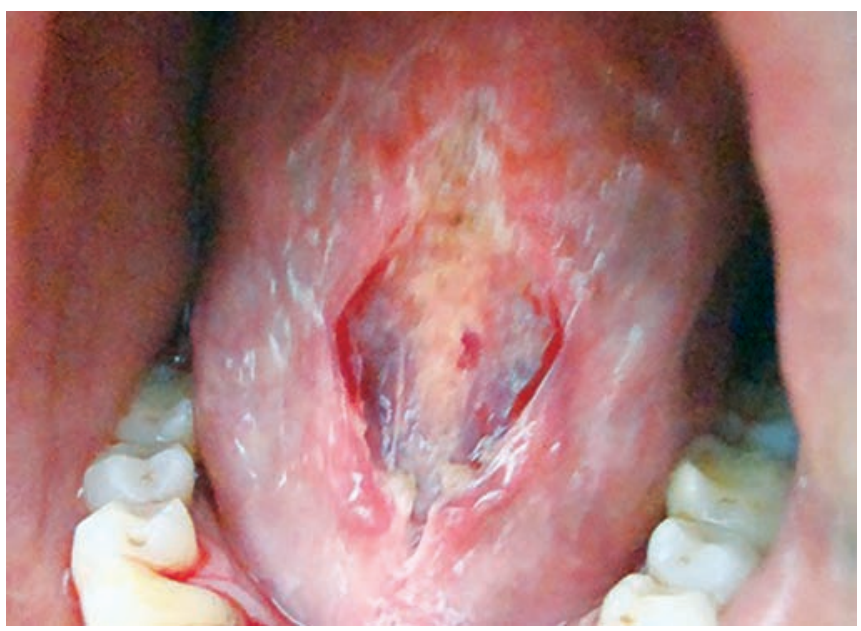

Fig. 7: Lingual frenectomy completed. Minimal bleeding spot with good haemostasis and visualization of the rhomboid-shaped wound (case 1)

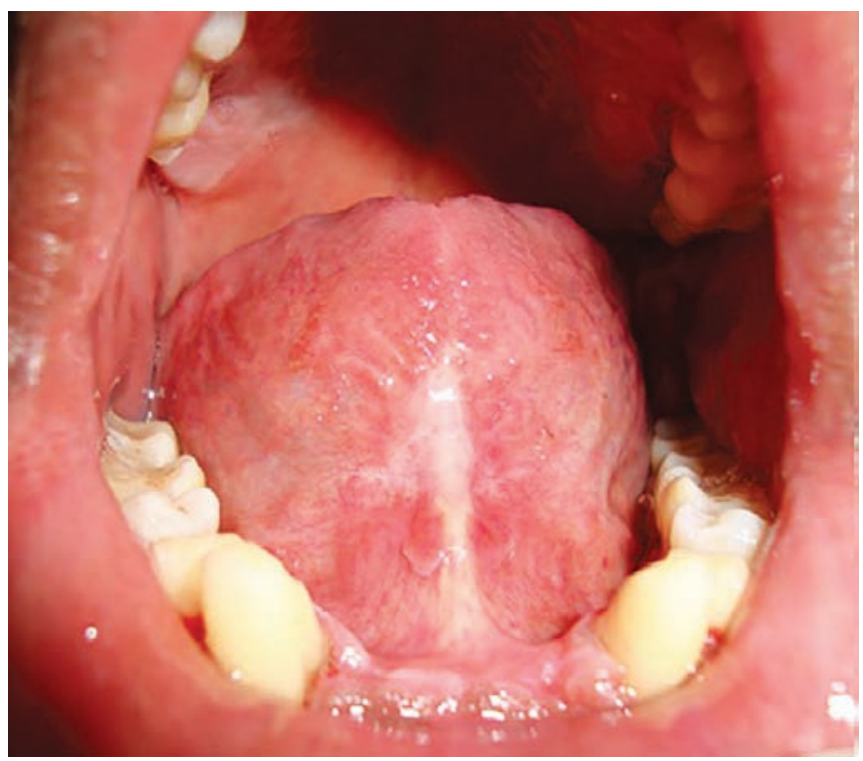

Fig. 9: One-week postoperative site (case 1)

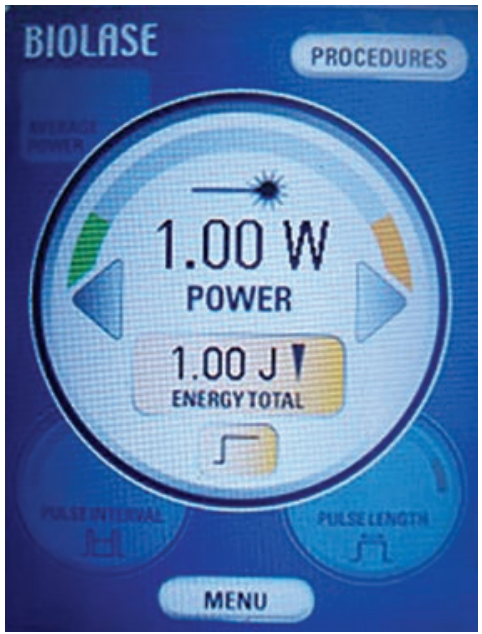

Fig. 6: Laser parameters used was $1 \mathrm{~W}$, continuous wave (case 1)

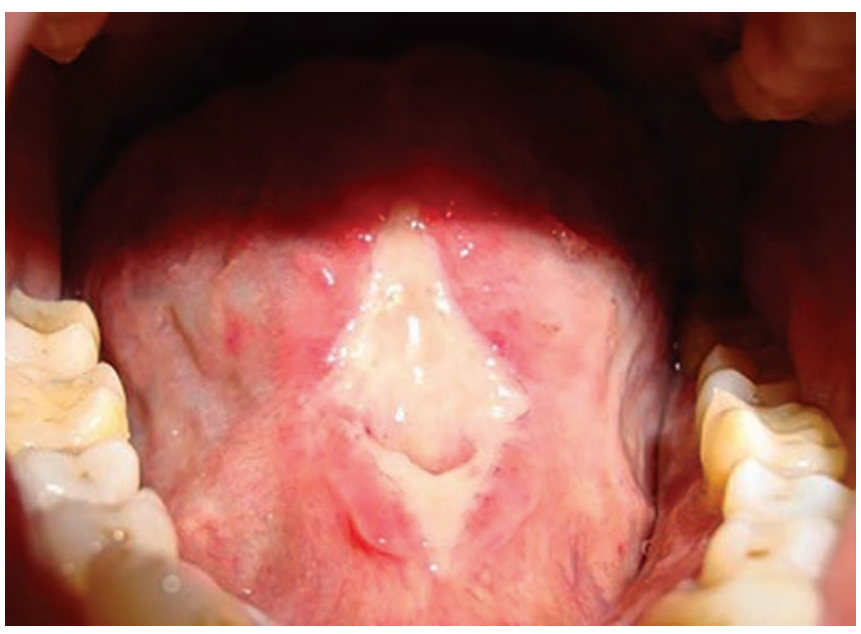

Fig. 8: One-day postoperative healing seen with laser bandaid (case 1)

sis. Laser troughing was done around the teeth prepared for crown to retract the marginal gingiva enabling good impression-making (Fig. 10). The patient was very satisfied with the complete approach to his dental issue and also his speech acceptance by his family. The patient was recalled 10 day postoperatively (Fig. 11) to view the treatment site and fix the prosthesis (Figs 12 and 13).

\section{Case 2}

A 24-year-old female patient had visited our dental clinic and complained about gaps in between her teeth (Figs 14 and 15). The patient wanted to have an orthodontic treatment to correct her dental alignment. On clinical examination, she had high frenal attachment on both labial and lingual frenums (Fig. 16), which were thick and short restricting the movement of the tongue (Figs 17 and 18). On protrusion of the tongue, classical W-shaped tongue 


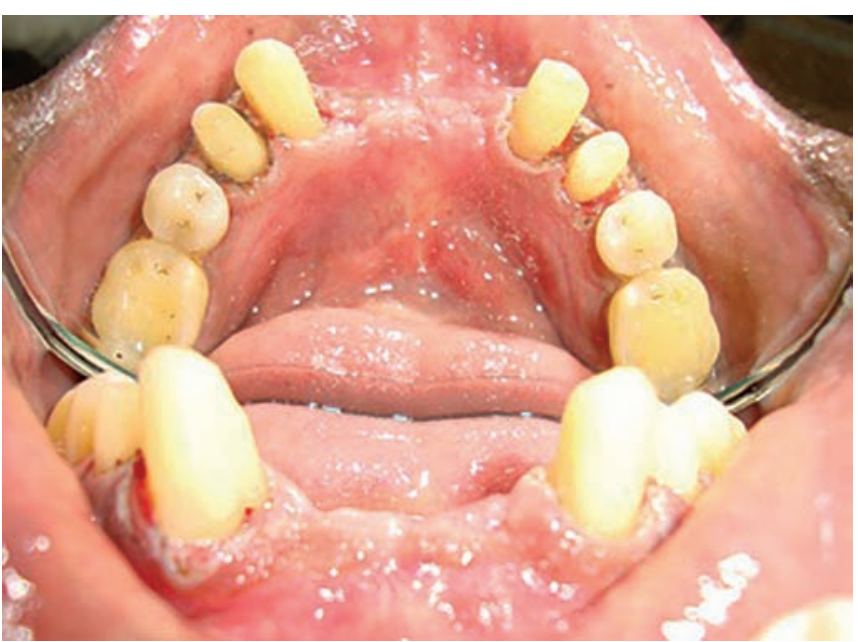

Fig. 10: Mirror image of the site after lingual frenectomy done. Crown preparation and laser troughing done on $33,34,43$, and 44 (case 1)

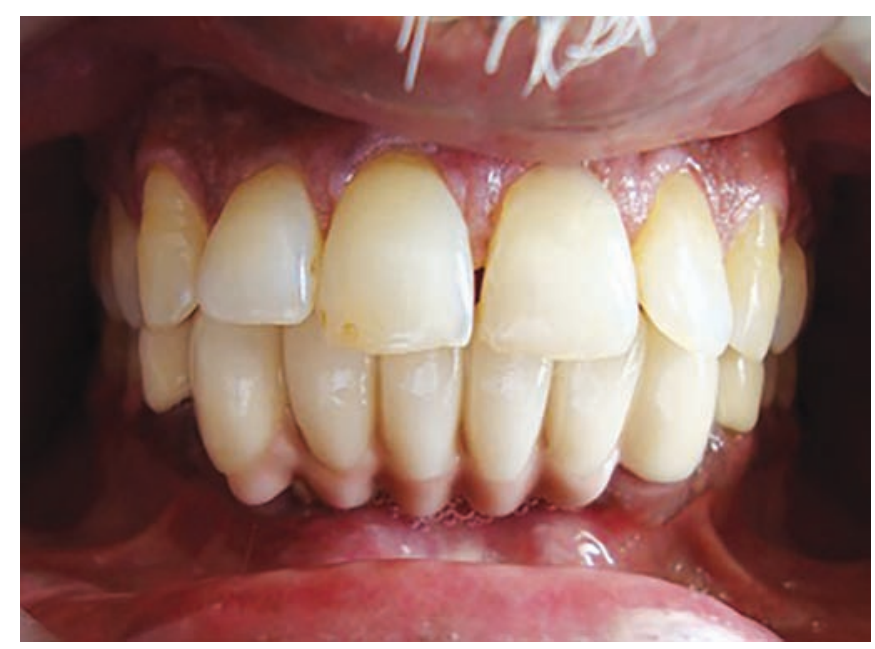

Fig. 12: Fixed partial prosthesis placed in treatment for the missing central and lateral incisors (case 1)

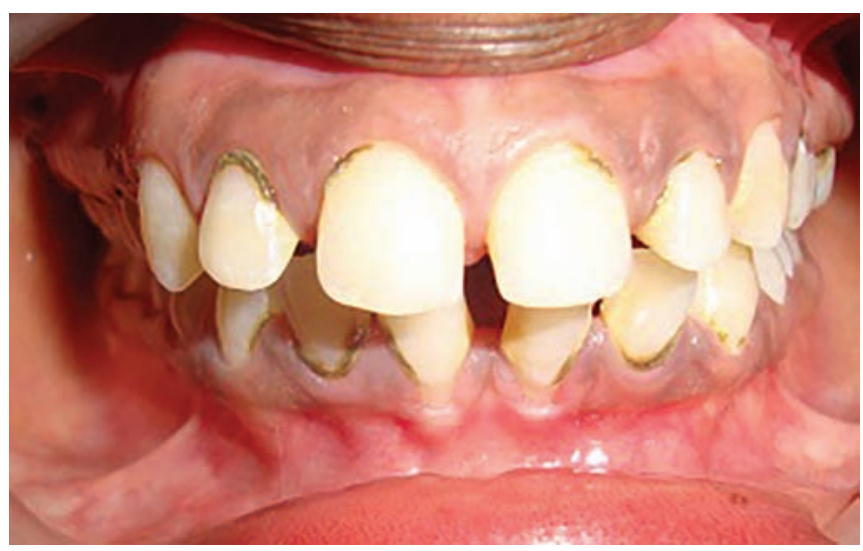

Fig. 14: Preoperative clinical view of the patient showing diastema between her upper and lower anteriors (case 2)

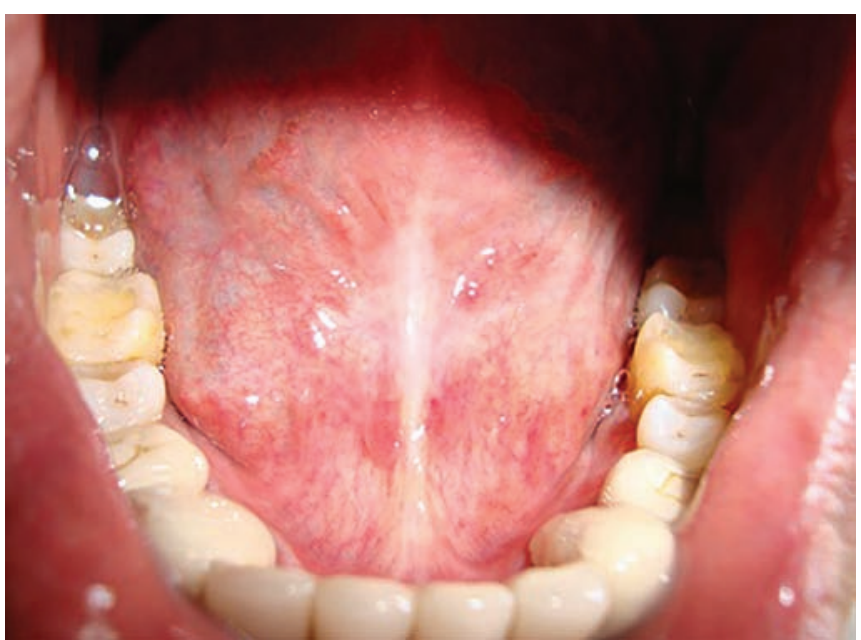

Fig. 11: Ten-day postoperative view of the frenectomy site (case 1)

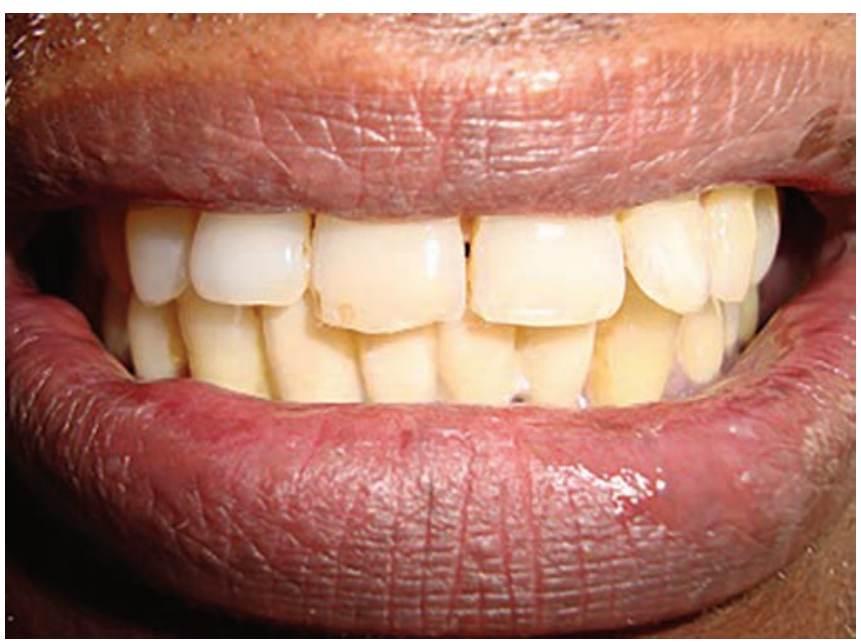

Fig. 13: Patient's teeth in occlusion with the prosthesis (case 1)

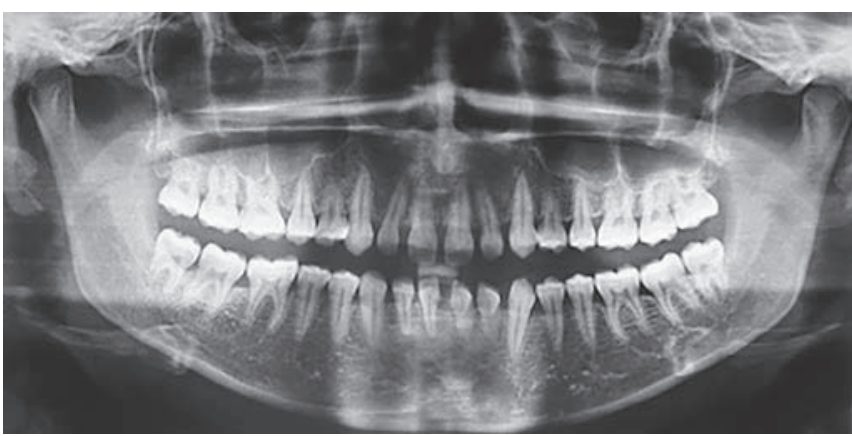

Fig. 15: Orthopantamograph showing spacing in between the maxillary and mandibular anterior teeth (case 2) 


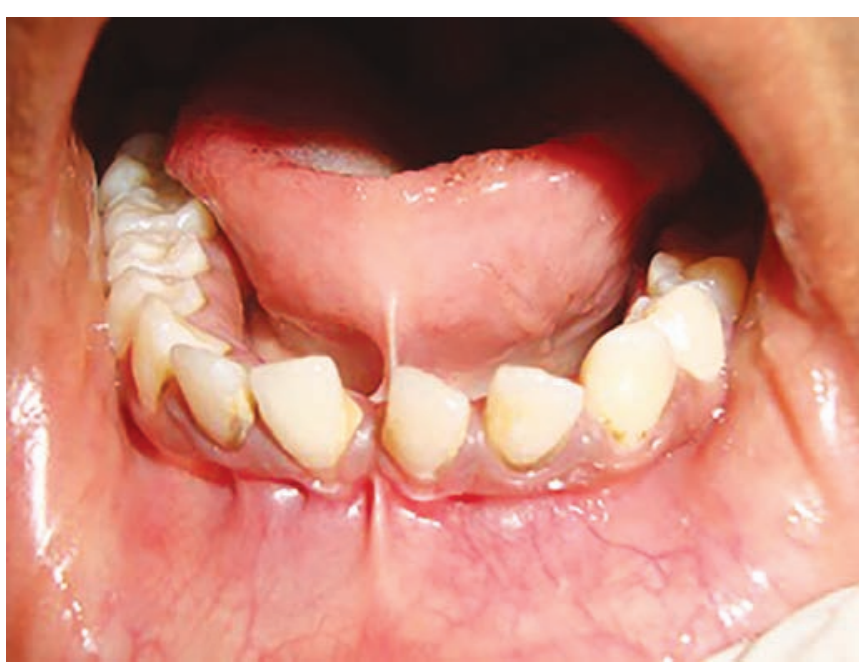

Fig. 16: High frenal attachment on both labial and lingual frenum in the lower anterior region (case 2)

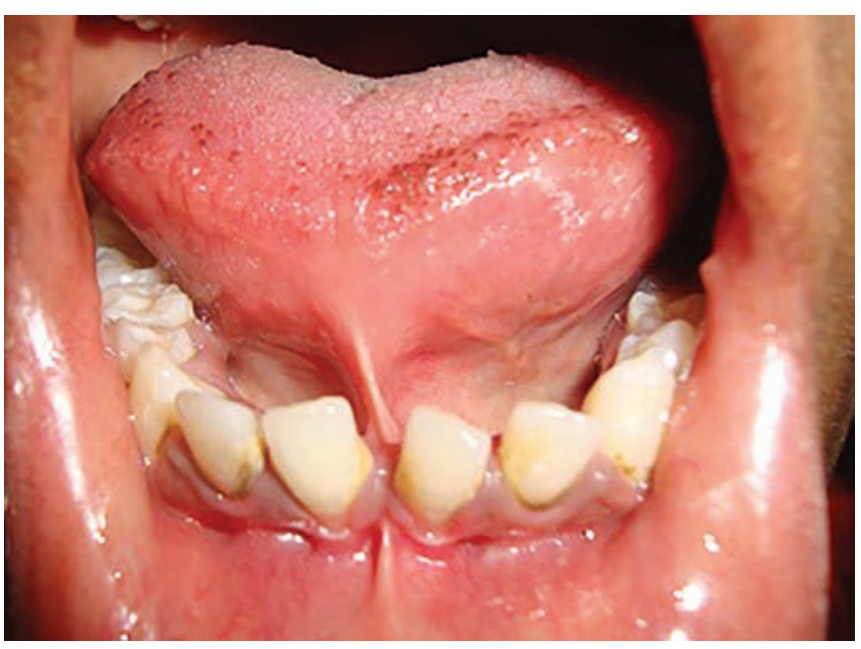

Fig. 18: Restricted tongue movement on elevation (case 2)

was seen (Fig. 19), which is characteristically observed in patients who cannot protrude the tongue tip beyond the edges of the lower incisors or to the maxillary alveolar ridge. The patient also had speech issues and was psychologically upset and anxious. General dental prophylaxis and treatment protocols were discussed with the patient. The lingual frenum was suggested to be removed either using traditional methods with scalpel and suturing done or with laser. The patient preferred to get the procedure done with lasers.

Er;Cr:YSGG (2,780 nm wavelength; Waterlase MD, Biolase, USA) all-tissue laser was used. Erbium laser comes under the class IV laser classification with power settings variable from 0.1 to $8.0 \mathrm{~W}$, pulse repetition rates or frequency of 10 to $50 \mathrm{~Hz}$ which can be selected by the clinician, with pulse duration of $140 \mu \mathrm{s}$ for $\mathrm{H}$ mode and $700 \mu$ s for $\mathrm{S}$ mode and pulse energy

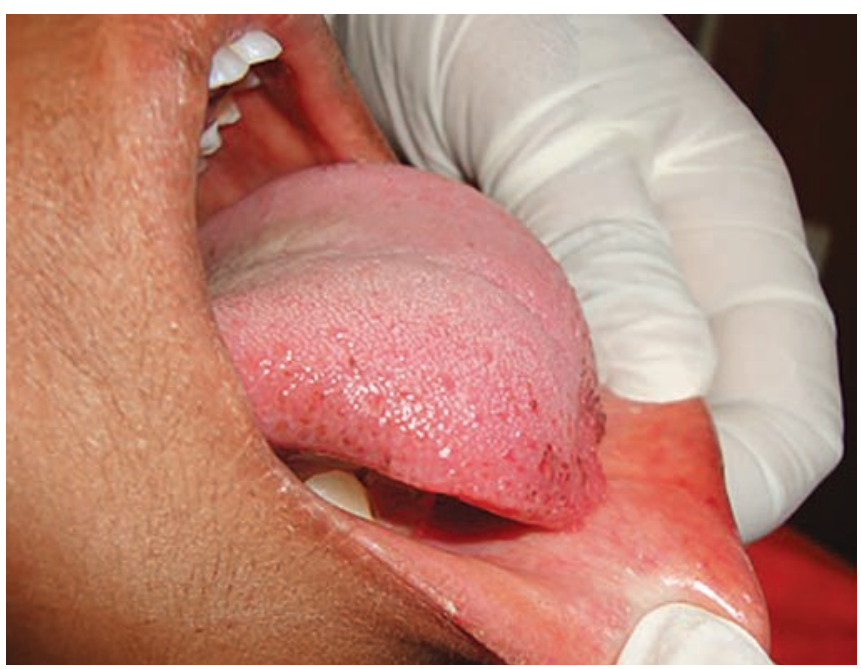

Fig. 17: Restricted tongue movement on protrusion (case 2)

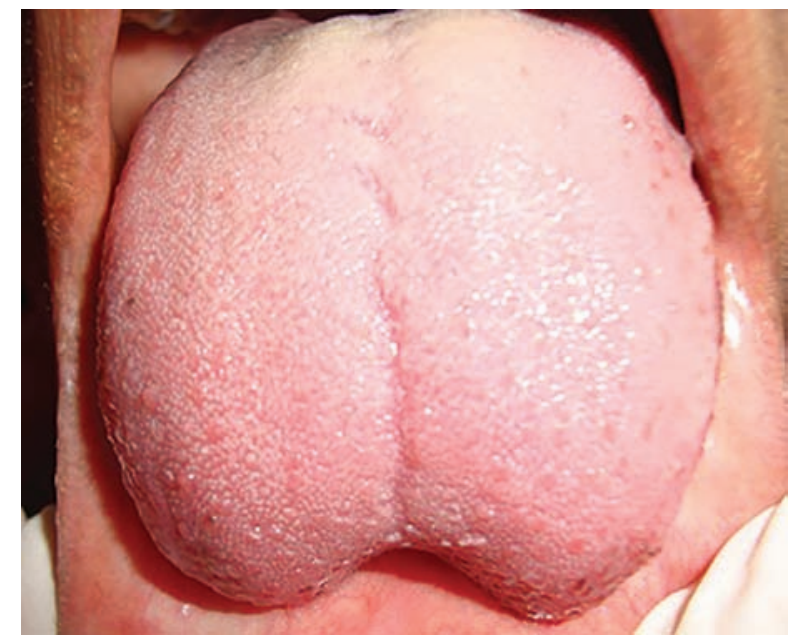

Fig. 19: Classical W-shaped tongue seen on protrusion due to the tongue tip being tied to the lingual frenum along with macroglossia (case 2)

of 0 to $300 \mathrm{~mJ}$. The laser safety officer should ensure all the laser safety protocols are met with before using the laser in operation.

Local anesthetic gel (Precaine - lidocaine $8 \%$, dibucaine $0.8 \%$ in a flavored aqueous base) was applied on the lingual frenum. The patient's tongue was held back to expose the frenum. The Er;Cr:YSGG laser with a gold handpiece and sapphire tip (Fig. 20) was used. The laser parameters (Fig. 21) of power $1.5 \mathrm{~W}$, frequency $50 \mathrm{~Hz}, \mathrm{~S}$ mode, $11 \%$ air, and $8 \%$ water was used to ablate the connective tissue in the frenum and to release the tongue. Caution was taken while performing this type of procedure due to adjacent anatomical soft tissue structures of clinical importance. Hence, in this case, Erbium lasers were preferred as they are subsurface lasers, and their penetration depth is less when compared to diode lasers. The Er;Cr:YSGG laser was used 


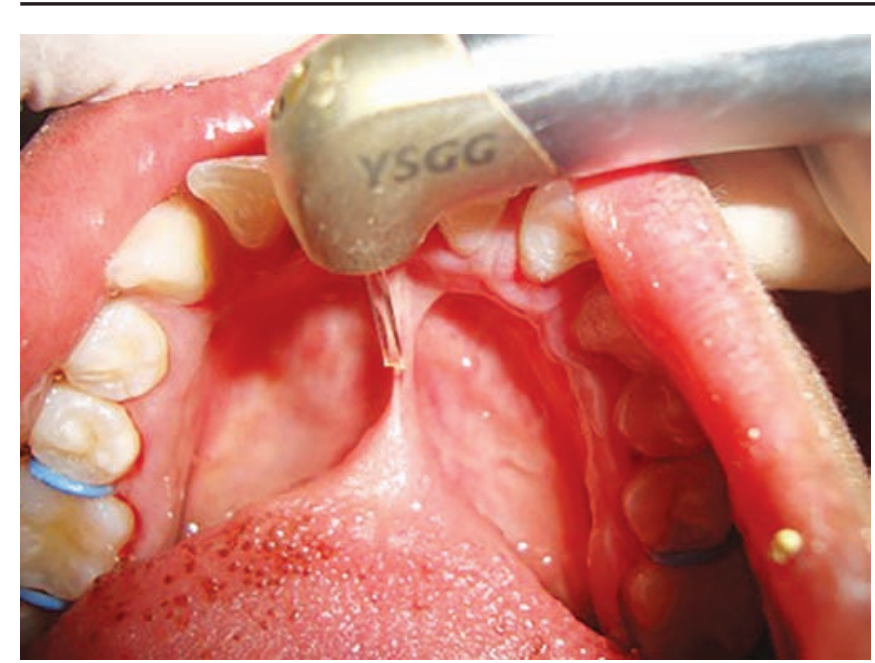

Fig. 20: Erbium laser with gold handpiece and sapphire tip used to perform frenectomy procedure (case 2)

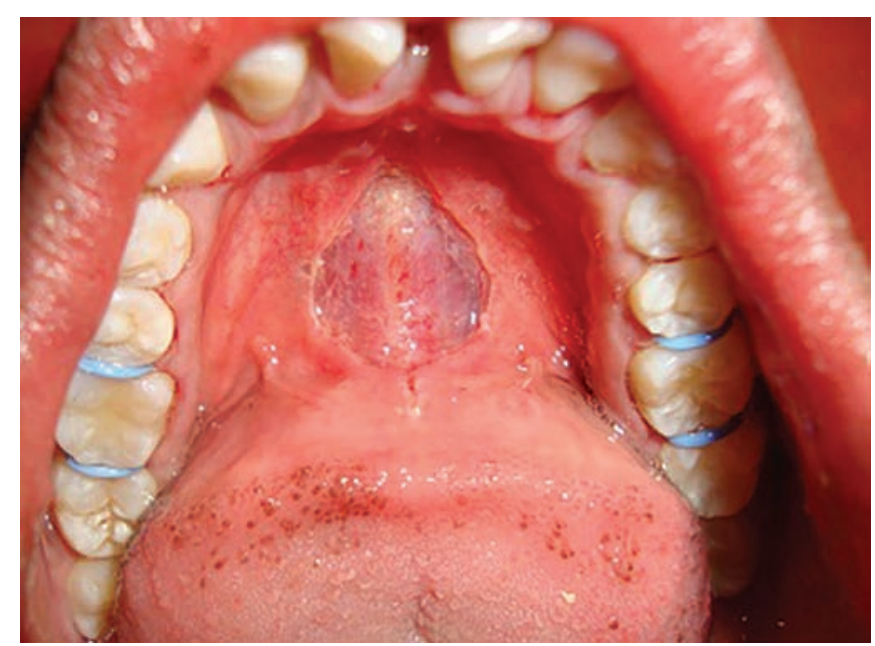

Fig. 22: Immediate postoperative view showing rhomboid shaped frenectomy site with good hemostasis (case 2)

to control bleeding, which was minimum in this case (Fig. 22). No sutures were necessary and patient discomfort was minimal or absent.

The patient had immediate improvement in tongue tip mobility (Fig. 23), extension, elevation, protrusion (Fig. 24), and speech. She was given postoperative instructions and exercises to extend the range of tongue motion with the help of the speech counselor. The patient was recalled after 3 days to see the postoperative wound healing (Fig. 25). The patient was comfortable and had got into her routine from the 1st day. When she returned 20 days later, healing was uneventful, and the patient stated that she was happy with her speech improvements and tongue movements (Fig. 26). Lasers help such patients with ankyloglossia to recover comfortably with significantly less postoperative complications in both infants and adults. Healing is faster and usually uneventful with lasers rather than a scalpel and there are no sutures to be placed or removed.

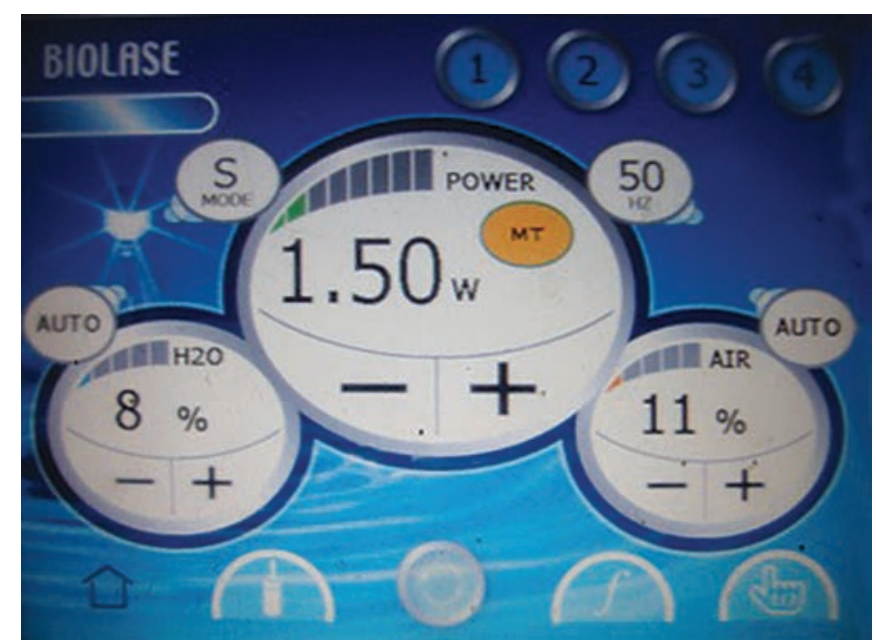

Fig. 21: Erbium laser parameters used was $1.5 \mathrm{~W}, \mathrm{~S}$ mode, $50 \mathrm{~Hz}, 8 \%$ water, and $11 \%$ air (case 2)

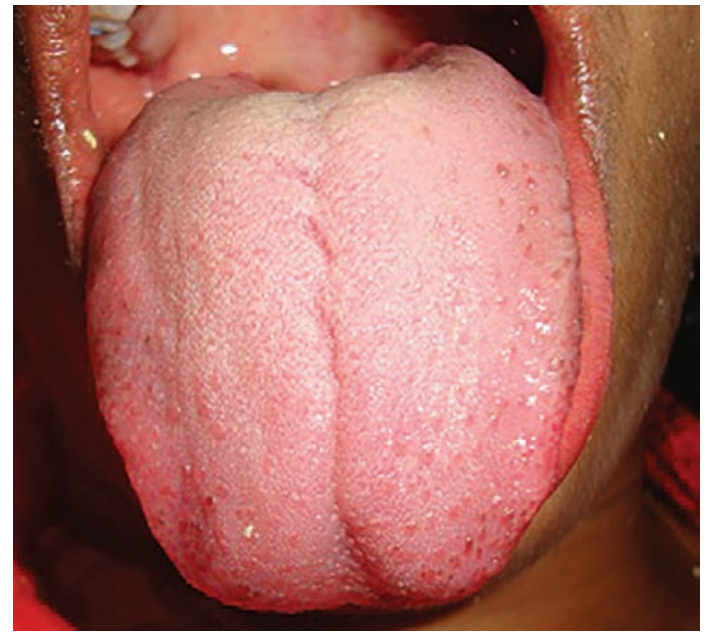

Fig. 23: Immediate postoperative view showing a relieved tongue tip (case 2)

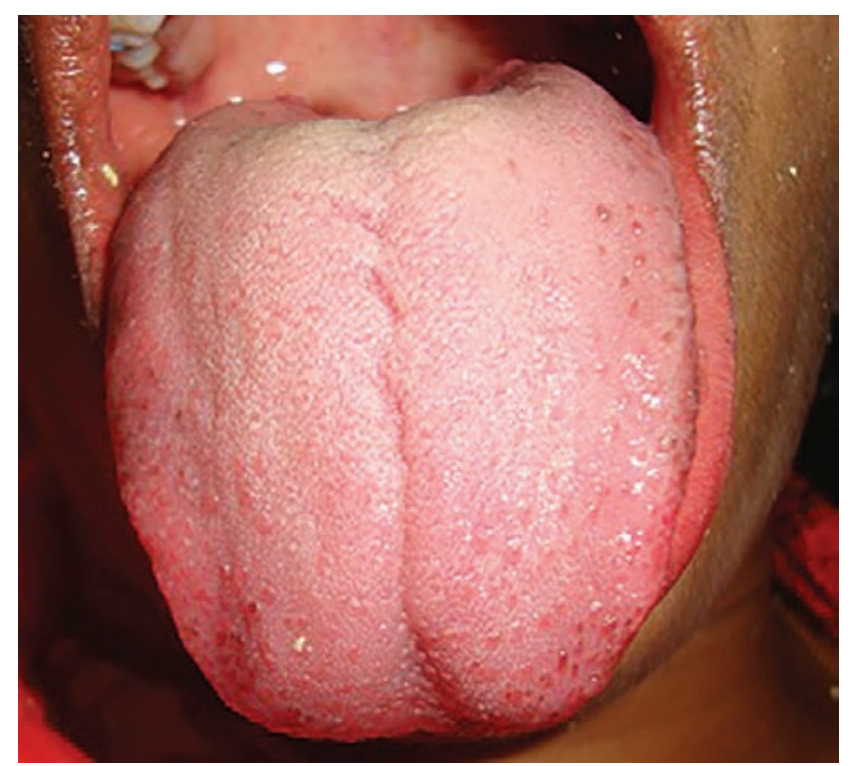

Fig. 24: Immediate postoperative view showing normal protrusion of the tongue laterally (case 2) 


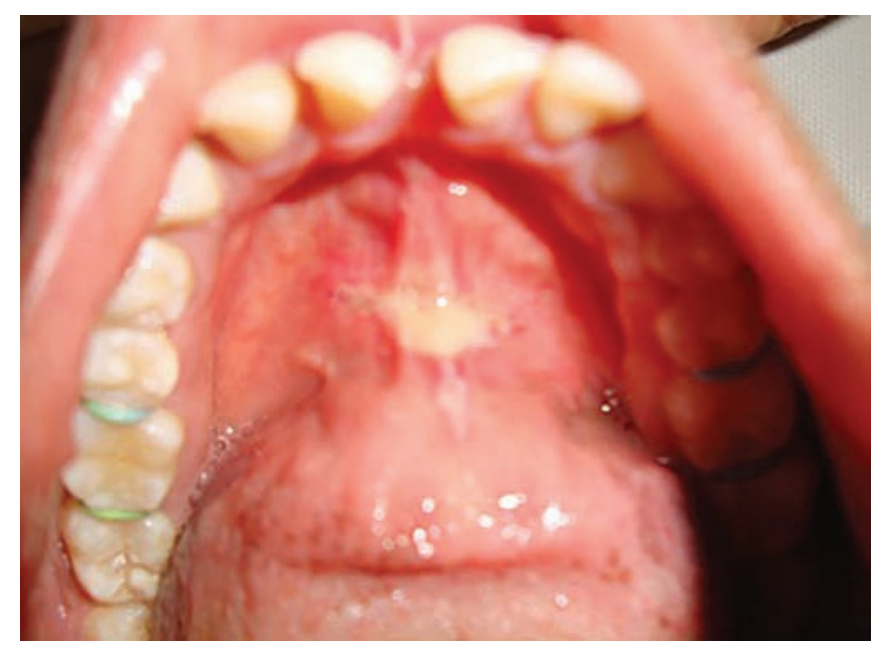

Fig. 25: Postoperative view after 3 days showing good wound healing (case 2)

Generally, lingual frenectomy is a safe procedure. The following complications are very rare, such as infection, bleeding, ulcer formation under the tongue, or any damage to the tongue. If no sutures are placed, a rhomboid-shaped wound will remain under the tongue. This wound takes 5 to 7 days to heal.

\section{RESULT}

The patients were recalled periodically to check for any discomfort and also monitor the movement of their tongue. A month after the surgery, the patients had an altered tongue shape with a free tongue tip and their movements had improved dramatically. Lip closure and speech along with phonetics had also improved.

\section{DISCUSSION}

This article highlights the use of both soft and hard tissue lasers in lingual frenectomy ${ }^{11}$ (Table 1). Diode lasers can produce quite a bit of heat and collateral damage to adjacent delicate tissues, whereas Er;Cr:YSGG laser produces significantly less heat generation and provides good hemostasis. The heat can be dissipated using high vacuum suction in diode lasers, which act as an external coolant. The patients can also be advised to rinse with cold water during the procedure. Hemoglobin is the chromophore for diode lasers and hence, the laser energy is quickly absorbed by the tissues bringing about hemostasis. Erbium lasers, however, work on the water chromophore, and by modifying the parameters, by reducing the water spray, and by increasing the air, hemostasis can be achieved with minimal or no collateral damage which further facilitates patient comfort. Lasers have an edge over conventional techniques due to better visibility of the treatment site during the procedure, thereby having much better precision in work. Lasers also contribute to uneventful healing

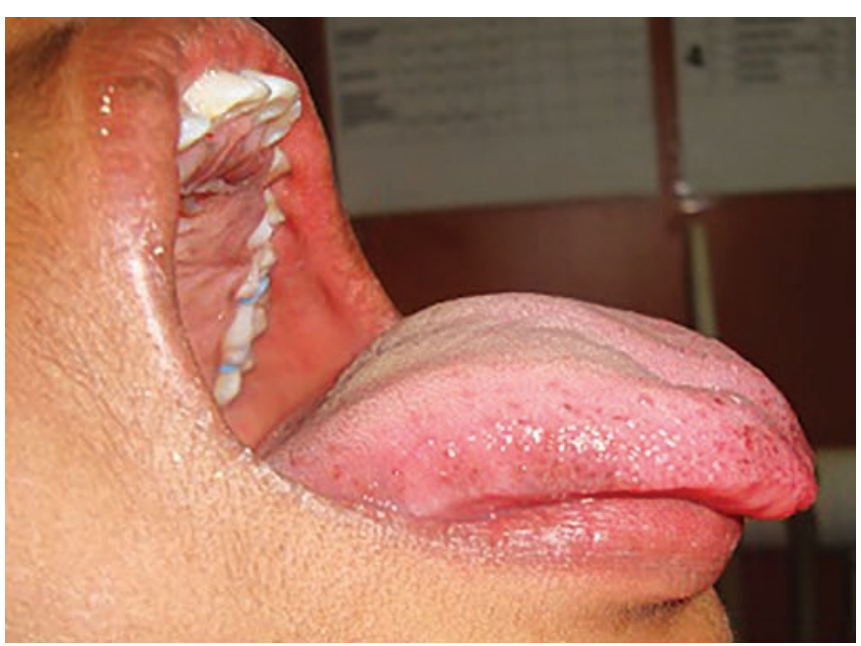

Fig. 26: Postoperative view showing normal protusion of the tongue (case 2)

Table 1: Basic advantages of using soft and hard tissue lasers for frenectomy procedure

\begin{tabular}{|c|c|c|}
\hline Tissue response & Soft tissue lasers & Hard tissue lasers \\
\hline $\begin{array}{l}1 \text { Depth of laser } \\
\text { penetration }\end{array}$ & $\begin{array}{l}\text { May vary } 15-25 \text { cell } \\
\text { layer deep }\end{array}$ & $\begin{array}{l}\text { Varies } 5-10 \text { cell } \\
\text { layer deep }\end{array}$ \\
\hline $\begin{array}{l}2 \text { Bleeding } \\
\text { during the } \\
\text { procedure }\end{array}$ & $\begin{array}{l}\text { The chromophore } \\
\text { being hemoglobin, } \\
\text { bleeding is less or } \\
\text { absent }\end{array}$ & $\begin{array}{l}\text { The chromophore } \\
\text { being water, } \\
\text { the bleeding is } \\
\text { minimized by } \\
\text { changing the } \\
\text { parameters, such as } \\
\text { reducing the water } \\
\text { and air components }\end{array}$ \\
\hline $\begin{array}{l}3 \text { Patient comfort } \\
\text { during the } \\
\text { procedure }\end{array}$ & $\begin{array}{l}\text { Diode lasers cause } \\
\text { thermal radiation in } \\
\text { the tissue and need } \\
\text { high vacuum suctions } \\
\text { to bring about thermal } \\
\text { relaxation }\end{array}$ & $\begin{array}{l}\text { The air and water } \\
\text { components act as } \\
\text { additional coolants, } \\
\text { thereby reducing } \\
\text { the heat and being } \\
\text { tissue-friendly }\end{array}$ \\
\hline 4 Pain & $\begin{array}{l}\text { The lasers generally } \\
\text { cause a tingling } \\
\text { sensation which } \\
\text { might be painful for } \\
\text { some patients }\end{array}$ & $\begin{array}{l}\text { The water flow } \\
\text { reduces the tingling } \\
\text { sensation }\end{array}$ \\
\hline $\begin{array}{l}5 \text { Postoperative } \\
\text { discomfort }\end{array}$ & $\begin{array}{l}\text { The healing is } \\
\text { uneventful and } \\
\text { comfortable }\end{array}$ & $\begin{array}{l}\text { The healing is } \\
\text { uneventful and } \\
\text { comfortable }\end{array}$ \\
\hline 6 Medications & $\begin{array}{l}\text { With lasers the } \\
\text { medication is usually } \\
\text { reduced as patients } \\
\text { are comfortable, } \\
\text { even in medically } \\
\text { compromised } \\
\text { conditions }\end{array}$ & $\begin{array}{l}\text { With lasers the } \\
\text { medication is usually } \\
\text { reduced as patients } \\
\text { are comfortable, } \\
\text { even in medically } \\
\text { compromised } \\
\text { conditions }\end{array}$ \\
\hline
\end{tabular}

of the wound due to the low-level laser therapeutical effect and being bactericidal in nature. The lingual frenulum alteration ranges from mild to severe and lingual frenectomy is definitely a mechanical alteration, which alters the tongue posture, tongue mobility, orofacial functions, lip posture which are improved to different degrees after 
frenectomy. Lasers have evolved as an alternative treatment modality for most oral surgical lesions due to the following advantages over conventional scalpel ${ }^{12}$ :

- Soft tissue cutting is efficient, with no bleeding giving a clear operative field;

- No need to use sutures or oral packs as Lasers weld the tissue;

- No postsurgical infection and no need for analgesics or antibiotics as lasers are bactericidal in nature;

- Wound contraction and scarring were decreased or eliminated, and better wound healing was seen because of lack of myofibroblasts in the wound; and

- Despite the initial slowness of the healing process due to more number of inflammatory cells, the complete and final recovery was faster and the healing in the ultrastructural level was completed only after 21 days.

\section{SPEECH THERAPY}

The tongue-tie makes articulation and phonetics a challenge. Hence, pronunciation of lingua-alveolar and lingua-palatal sounds, such as $/ \mathrm{r} /$ or $/ 1 /$, is a major concern. Frenectomy is commonly used on newborn infants in the United States and other countries to make breastfeeding ${ }^{13-15}$ more successful and comfortable, both for the infant and its mother.

Speech may be defined as a complex psychophysiological process for putting thoughts into words and organizing these words into a sequence with grammatical context. The physiological media of speech are respiratory, phonatory, articulatory, and resonatory. The teeth, in conjugation with the lips and tongue, play an important role in the articulation of consonants by airflow obstruction and modification.

Ankyloglossia ${ }^{16}$ is a condition where the length of the lingual frenulum hinders with speech production. It is a congenital anomaly that presents various speech and nonspeech (feeding/swallowing) symptoms based on the severity. Speech production is impaired based on the extent to which the frenulum restricts the range of movement of the tongue. Tongue length is based on Kotlow's ${ }^{17}$ classification which classifies:

Normal range of free tongue $>16 \mathrm{~mm}$

Class I: Mild ankyloglossia $=12$ to $16 \mathrm{~mm}$

Class II: Moderate ankyloglossia $=8$ to $11 \mathrm{~mm}$

Class III: Severe ankyloglossia $=3$ to $7 \mathrm{~mm}$

Class IV: Complete ankyloglossia $<3 \mathrm{~mm}$

Darshan and Pavithra ${ }^{18}$ report that postoperative exercises following tongue-tie surgery are not intended to increase muscle-strength, but to:

- Develop new muscle movements, particularly those involving tongue-tip elevation and protrusion, inside and outside of the mouth.
- Increase kinesthetic awareness of the full range of movements the tongue and lips can perform. Kinesthetic awareness refers to knowing where a part of the mouth is, what it is doing, and what it feels like.

- Encourage tongue movements related to cleaning the oral cavity, including sweeping the insides of the buccal mucosa, the labial and lingual surfaces of the teeth, and licking around both lips.

Given the minor nature of the surgery and significant potential for speech difficulties and later social and mechanical problems, it may be appropriate to consider surgery for children with significant tongue-tie at any age, including infants and toddlers ${ }^{19}$ who have yet to demonstrate overt symptoms. In general, for individuals who undergo frenectomy/frenotomy, ${ }^{20}$ speech therapy is commenced after assessment protocol, which involves examination of lingual functioning for vegetative skills and speech production as well. The following are few nonspeech oromotor exercises that were executed for improving tongue strength, mobility, and range of movement ${ }^{21}$ :

- Oral play - different tongue movements including protrusion, retraction, lateral movements, elevation, and lowering position. Following these basic movement exercises, movement of tongue with opposing force is performed in order to increase the tongue strength. This is performed either by pressuring the protruded tongue using a tongue depressor or by pressing the tongue (inside the oral cavity) against the cheeks with minimal pressure given using the thumb from outside.

- Other oral play activities include:

- Inward rolling of tongue tip;

- Blowing a whistle;

- Holding liquids/semisolids in oral cavity and then rotating the tongue in clockwise and anticlockwise patterns. ${ }^{22}$

\section{ARTICULATION THERAPY}

Before commencing articulation ${ }^{23}$ assessment protocol for any individual, the following list of aspects ${ }^{24}$ is considered:

- Age;

- Language used (mother tongue and other language(s) that the person is exposed to);

- Vocabulary and accent; and

- Familiarity of words (highly common words vs least used words).

Speech $^{25,26}$ (articulation) therapy plan includes assessment of phonetic placement and precise production of 
the speech sounds as well. Production of all the speech sounds is listed and assessed in the following hierarchy:

Example: Considering " $s$ " as the target speech sound

- Isolation level (e.g., ssssssssssss);

- Syllable level (e.g., sa, si, su, so);

- Word level (initial/medial and final positions of the word - e.g., sit, muscle and bus);

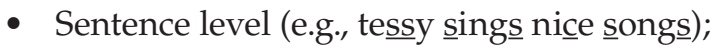

- Connected speech/spontaneous speech.

During speech production, lingua-alveolar sounds $\left(' t ', d^{\prime}, n^{\prime}\right)$ are produced with the top of the tongue tip, and therefore, they can be produced with very little tongue elevation or mobility. ${ }^{27}$ The fricative sounds ' $s$ ' and ' $\mathrm{z}$ ' require the tongue tip to be elevated only slightly, but can be produced with little distortion if the tip is down. Most the tongue tip needs to elevate is to the alveolar ridge for production of lingua-alveolar sound ' 1 ', lingua-palatal sound ' $r$ ', and lingua-dental sound 'th'.

Based on the assessment results, articulation therapy ${ }^{28}$ is planned for the speech sounds ranging from sounds that requires minimal effort of the tongue movement (e.g., lingua-alveolar liquids - ' 1 ') to increasing tongue effort and movement (e.g., lingua-palatal retroflex - ' $\mathrm{r}$ '). The prognosis of articulation therapy for individuals with misarticulation due to ankyloglossia is purely based on the each individual's self-interest, effort, adaptation to correct phonetic placement for precise speech sound production, and effective follow-up.

Optimal management ${ }^{29,30}$ of tongue-tie, including timely and appropriate surgical intervention, followed by speech therapy when indicated, has the capacity to deliver pleasing results, often in a shorter time than expected. Despite the fact that speech impediment is rare nevertheless for the mere purpose of dental toilette, oral and buccal hygiene, gesture, and even future intimacy functions, every child deserves the privilege to be able to protrude his/her tongue.

\section{CONCLUSION}

Frenectomy is reliably a predictable and efficient procedure which improves tongue posture, tongue mobility, oral functions, and communication, and it allows the tongue a wider range of motion. This procedure is increasingly becoming more common and popular due to the tongue-piercing craze among the younger population. Lasers have paved a way for the youth to experiment with such procedures in a tissue-friendly way, causing minimal damage to the surrounding tissues.

\section{ACKNOWLEDGMENT}

Author would like to personally thank Dr. Padmapriya R, Assistant Doctor at Smile Dental Clinic, for her untiring assistance during the treatment of both cases.

\section{REFERENCES}

1. Buryk M, Bloom D, Shope T. Efficacy of neonatal release of ankyloglossia: a randomized trial. Pediatrics 2011 Aug;128(2): 280-288.

2. Chaubal TV, Dixit MB. Ankyloglossia and its management. J Indian Soc Periodontol 2011 Jul-Sep;15(3):270-272.

3. Dolberg S, Botzer E, Grunis E, Mimouni F. A randomized, prospective, blinded clinical trial with cross-over of frenotomy in ankyloglossia: effect on breast-feeding difficulties. Pediatr Res 2002;52(5):822-827.

4. Wright JE. Tongue-tie. J Paediatr Child Health 1995 Aug;31(4): 276-278.

5. Johnson PRV. Tongue-tie - exploding the myths. Infant 2006;2(3):96-99.

6. Ballard JL, Auer CE, Khoury JC. Ankyloglossia: assessment, incidence, and effect of frenuloplasty on the breastfeeding. Pediatrics 2002 Nov;110(5):e63.

7. Dolberg S, Botzer E, Grunis E, Mimouni FB. Immediate nipple pain relief after frenotomy in breast-fed infants with ankyloglossia: a randomized, prospective study. J Pediatr Surg 2006 Sep;41(9):1598-1600.

8. Geddes DT, Langton DB, Gollow I, Jacobs LA, Hartmann PE, Simmer K. Frenulotomy for breastfeeding infants with ankyloglossia: effect on milk removal and sucking mechanism as imaged by ultrasound. Pediatrics 2008 Jul;122(1):188-194.

9. Knox I. Tongue tie and frenotomy in the breastfeeding newborn. Neo Rev 2010;11(9):e513-e519.

10. Hooda A, Rathee M, Yaday S, Gulia J. Ankyloglossia: a review of current status. Int J Otorhinolaryngol 2010;12(2).

11. Aras MH, Goregen M, Güngörmüş M, Akgul HM. Comparison of diode laser and Er:YAG lasers in the treatment of ankyloglossia. Photomed Laser Surg 2010 Apr;28(2): 173-177.

12. De Santis D, Gerosa R, Graziani PF, Zanotti G, Rossini N, Castellani R, Bissolotti G, Chiarini L, Nocini PF, Bertossi D. Lingual frenectomy: a comparison between the conventional surgical and laser procedure. Minerva Stomatol 2013 Aug 1.

13. Marmet C, Shell E, Marmet R. Neonatal frenotomy may be necessary to correct breast feeding problems. J Hum Lact 1990 Sep;6(3):117-121.

14. Messner AH, Lalakea ML, Aby J, Macmahon J, Bair E. Ankyloglossia: incidence and associated feeding difficulties. Arch Otolaryngol Head Neck Surg 2000 Jan;126(1):36-39.

15. O'Callahan C, Macary S, Clemente S. The effects of officebased frenotomy for anterior and posterior ankyloglossia on breastfeeding. Int J Pediatr Otorhinolaryngol 2013 May;77(5):827-832.

16. Lalakea ML, Messner AH. Ankyloglossia: does it matter? Pediatr Clin North Am 2003 Apr;50(2):381-397.

17. Kotlow LA. Ankyloglossia (tongue-tie): a diagnostic and treatment quandary. Quintessence Int 1999 Apr;30(4): 259-262.

18. Darshan HE, Pavithra PM. Tongue tie: from confusion to clarity - a review. Int J Dent Clin 2011 Jan-Mar;3(1):48-51.

19. Kupietzky A, Botzer E. Ankyloglossia in the infant and young child: clinical suggestions for diagnosis and management. Pediatr Dent 2005 Jan-Feb;27(1):40-46.

20. Masaitis NS, Kaempf JW. Developing a frenotomy policy at one medical center: a case study approach. J Hum Lact 1996 Sep;12(3):229-232. 
21. Segal LM, Stephenson R, Dawes M, Feldman P. Prevalence, diagnosis, and treatment of ankyloglossia: methodologic review. Can Fam Physician 2007 Jun;53(6):1027-1033.

22. Steehler MW, Steehler MK, Harley EH. A retrospective review of frenotomy in neonates and infants with feeding difficulties. Int J Pediatr Otorhinolaryngol 2012 Sep;76(9): 1236-1240.

23. Lee HJ, Park HS, Park BS, Choi JW, Koo SK. The improvement of tongue mobility and articulation after frenotomy in patient with ankyloglossia. J Otorhinolaryngol Head Neck Surg 2010;53:491-496.

24. American Academy of Pediatric Dentistry (AAPD). Guideline on pediatric oral surgery. Chicago (IL): American Academy of Pediatric Dentistry (AAPD); 2010.

25. Marchesan IQ. Lingual frenulum: classification and speech interference. Int J Orofacial Myology 2004 Nov;30:31-38.
26. Messner AH, Lalakea ML. The effect of ankyloglossia on speech in children. Otolaryngol Head Neck Surg 2002 Dec;127(6):539-545.

27. Olivi G, Signore A, Olivi M, Genovese MD. Lingual frenectomy: functional evaluation and new therapeutical approach. Eur J Paediatr Dent 2012 Jun;13(2):101-106.

28. Suter VG, Bornstein MM. Ankyloglossia: facts and myths in diagnosis and treatment. J Periodontol 2009 Aug;80(8): 1204-1219.

29. Messner AH, Lalakea ML. Ankyloglossia: controversies in management. Int J Pediatr Otorhinolaryngol 2000 Aug;54(2-3): 123-131.

30. Newkirk GR. Tongue-tie snipping (frenotomy) for ankyloglossia. In: Pfenninger JL, editor. Procedures for primary care physicians. 1st ed. St. Louis (MO): Mosby-Year Book Inc.; 1994. p. 287-290. 